\title{
Faith-Based Organisations (FBO): A Review of Literature on their Nature and Contrasting Identities with NGO in Community Development Intervention
}

\author{
Asma Lailee Mohd. Noor \\ lailee@umk.edu.my \\ Noor Hisham Md Nawi \\ hisham@umk.edu.my \\ (Universiti Malaysia Kelantan)
}

\begin{abstract}
Organizations with a faith basis play a dominant role within the development sector. In the latter half of the twenty-first century, many faith-based organizations (FBOs), motivated by their religious faith and beliefs, began to work beyond their own borders to improve the material well-being of the world's poor. However, despite the significant presence of FBOs within the arena of aid and development, little agreement exists within the development literature as to the similarity or distinction between aid agencies that are faith based and secular. This study reviews the existing literature on the nature of the FBOs in order to analyse how FBOs are understood in relation to NGOs. It also suggests a number of different typologies that captures these diverse ranges of views of how FBOs are understood.
\end{abstract}

Keywords: faith-based organisations, nongovernmental, community development,

\section{Introduction}

Community development is a process that entails organization, facilitation, and action, which allows people to establish ways to create the community they want to live in. It is a process that provides vision, planning, direction, and coordinated action towards desired goals associated with the promotion of efforts aimed at improving the conditions in which local resources operate. It is very synonym with the alleviation of poverty and the establishment of equal opportunities and equitable distribution of economics and social rewards, which is also an on-going issue for all countries. Indeed in September 2000, alarmed by growing global poverty and a widening in the gap between the rich and the poor, the United Nations launched its Millennium Project, which called on member states to eradicate poverty and hunger, reduce the incidence of disease, provide universal primary education for children, create a healthier environment, and encourage global partnership for continued development. In those nations whose histories include strained relations among diverse ethnic and racial groups, the problems of economics and social inequity are especially salient.

As noted by Soon (2005), the problem outlined by the UN Millennium Project have been recognized by all government leaders. Series of development plans reflect the on-going concerns with these problems. All nations are still trying their best in reducing poverty rates, increasing adult literacy rates, and perhaps more importantly pursuing policies of inclusion for all racial and ethnic groups while advancing in economic growth and development. This is not to deny that a number of chronic problems remain. Policies that sought to bring a greater proportion of primarily rural residents into a decent standard of living have not always had the intended results.

On the basis of the framework outline by Lea and Chaudri (1983), there were mixture of approaches in community development intervention from those of technocratic model to reformist and free market. Generally the approaches had been relatively free market model before 1950s, then shifted towards technocratic and reformist models towards the end of 1960 s to 1990 , and reemphasis on free market model during the post-1990. The emphasis on community development approaches tended to varies from different period of development although we can trace the overlapping in the approaches. 
In the current phase of community development, within the general development framework of neo-liberal and globalization of the economy, community development has tended to provide more ground for free market approach with the development of infrastructure and incentives for private capitals in rural areas. It aims to receive priority for public investment and policy support (Ngah, 2012). However, the main players and funding will come from the private sector with public sector investment as catalyst to spark private sector participation. In this case, the private sector includes private agencies and non-governmental organisations.

\section{NGO: An Actor in Community Development Intervention}

The government is not the only actor in its effort to ensure a balanced development to all folks of life. It has been trying very hard in order to bridge the gap between urban and rural, and between the rich and the poor.

The last 20 years have seen the emergence of a new category of actors on the community development stage. As noted by Meyer (2012), participation by nongovernmental organisations (NGOs) in community development has intensified significantly during the last two decades. A nongovernmental organisation is not-for-profit, voluntary citizens' group, which is organised on a local, national, or international level to address issues in support of the public good. Task-oriented and made up of people with common interests, NGOs perform a variety of services and humanitarian functions, bring citizens' concerns to governments, monitor policy and program implementation, and encourage participation of civil society stakeholders at the community level. They provide analysis and expertise, serve as early warning mechanisms, and help monitor and implement agreements (Hilton, 2012).

Their number has grown exponentially; the size of some of them makes them significant players in social welfare and employment market at the national level; the funding they attract has increased enormously; and their visibility to the general public has never been higher. NGOs are perceived as having two distinctive features that differentiate them from other community developers. First, they are advocates of the most vulnerable populations and their motivation is widely perceived as mainly altruistic. Second, their actions at the grassroots level are seen as conducted at private-sector level of cost control and efficiency, while they achieve development objectives and serve the needs of many people.

History of NGO establishment could be traced back to 1945 when the United Nations (UN) was created. Later the term became used more widely. Today, according to the UN, any kind of private organization that is independent from government control can be termed an "NGO", provided it is not-for-profit, non-prevention, and not simply an opposition political party. Since then, there are many variations of nongovernmental organisations has been substantiated across the nation.

NGOs types can be understood by their orientation and level of how they operate. There are four orientations in NGOs which could be identified as charitable, service, participatory, and empowering. Charitable orientation often involves a topdown paternalistic effort with little participation by the beneficiaries. It includes NGOs with activities directed toward meeting the needs of the poor peoples. Service orientation includes NGOs with activities such as the provision of health, family planning or education services in which the program is designed by the NGO and people are expected to participate in its implementation and in receiving the service. Participatory orientation is characterized by self-help projects where local people are involved particularly in the implementation of a project by contributing cash, tools, land, materials, labor, etc. In the classical community development project, participation begins with the need definition and continues into the planning and implementation stages. Empowering orientation aims to help poor people develop a clearer understanding of the social, political and economic factors affecting their lives, and to strengthen their awareness of their own potential power to control their lives. There is maximum involvement of the beneficiaries with NGOs acting as facilitators.

Operation of NGOs could be categorized into four levels; community-based, city-wide, national, and international. Community-based organizations arise out of people's own initiatives. They can be responsible for raising the consciousness of the urban poor, helping them to understand their rights in accessing needed services, and providing such services. Citywide organizations include organizations such as chambers of commerce and industry, coalitions of business, ethnic or educational groups, and associations of community organizations. National NGOs include national organizations such as the YMCAs/YWCAs, professional associations, and similar groups. Some have state and city branches and assist local NGOs. International NGOs range from secular agencies such as Ducere Foundation and Save the 
Children organizations, OXFAM, CARE, Ford Foundation, and Rockefeller Foundation to religiously motivated groups. They can be responsible for funding local NGOs, institutions and projects and implementing projects.

There are also numerous classifications of NGOs. The typology the World Bank uses divides them into Operational and Advocacy. Operational NGOs seek to achieve small-scale change directly through projects. They mobilize financial resources, materials, and volunteers to create localized programs. They hold large-scale fundraising events and may apply to governments and organizations for grants or contracts to raise money for projects. They often operate in a hierarchical structure; a main headquarters being staffed by professionals who plan projects, create budgets, keep accounts, and report and communicate with operational fieldworkers who work directly on projects. Operational NGOs deal with a wide range of issues, but are most often associated with the delivery of services or environmental issues, emergency relief, and public welfare. Operational NGOs can be further categorized by the division into relief-oriented versus development-oriented organizations; according to whether they stress service delivery or participation; whether they are religious or secular; and whether they are more public or private-oriented. Although operational NGOs can be community-based, many are national or international. The defining activity of operational NGOs is the implementation of projects.

Campaigning NGOs seek to achieve large-scale change promoted indirectly through influence of the political system. Campaigning NGOs need an efficient and effective group of professional members who are able to keep supporters informed, and motivated. They must plan and host demonstrations and events that will keep their cause in the media. They must maintain a large informed network of supporters who can be mobilized for events to garner media attention and influence policy changes. The defining activity of campaigning NGOs is holding demonstrations. Campaigning NGOs often deal with this issues relating to human rights, women's rights, children's rights. The primary purpose of an Advocacy NGO is to defend or promote a specific cause. As opposed to operational project management, these organizations typically try to raise awareness, acceptance and knowledge by lobbying, press work and activist event (Davies, 2014).

Another typology which can be used to understand NGOs is that there are faith based and secular NGOs. Organizations with a faith basis play a dominant role within the development sector. In the latter half of the twenty-first century, many faithbased organizations (FBOs), motivated by their religious faith and beliefs, began to work beyond their own borders to improve the material well-being of the world's poor. However, despite the significant presence of FBOs within the arena of aid and development, little agreement exists within the development literature as to the similarity or distinction between aid agencies that are faith based and secular. This study reviews the existing literature on the nature of the FBOs in order to analyse how FBOs are understood in relation to NGOs. It also suggests a number of different typologies that captures these diverse ranges of views of how FBOs are understood.

\section{Methodology}

This study employed textual and discourse analysis to gather information and to see the underlying themes and Keywords which contributed to the production of a critical compilation of works written by scholars and intellectuals worldwide concerning the nature of faith based organisations and the extent of their relations to nongovernmental organisations.

\section{FBO: A Clearer Vision of Its Nature}

It has been proposed that welfare services constitutes a site where the sacred and secular interact (Angell, 2010 p. 75), but as the above quote suggests, just what distinguishes a so-called faith-based organization from other services may not be readily apparent. Nor is there any consensus as to what the term faith-based organization means or even whether it is an appropriate term to describe initiatives of religious groups for whom faith is not a key component of their religion (Alison, 2010).

That faith is often regarded as synonymous with religion reflects the overwhelming influence of Christianity, Islam, and Judaism in the literature about welfare provision by religious organizations, and a lack of recognition that faith is not necessarily the most important tenet in some other religions (Jawad, 2009). But some have proposed that the focus on faith reflects a predominantly Protestant and Western perspective in the literature (Zain, 2012). 
Hence, it is important to clarify at the outset in using the term faith-based organization, this study is referring to a community service agency which employs qualified community workers and has its identity and mission, self-consciously derived from the teachings of one or more religious or spiritual traditions or is auspice by any religious organization or religious community. In addition to welfare organizations established by religious organizations, in some countries there is also a tradition of philanthropic established by the urban bourgeoisie or nobility which take their inspiration from, and identify with, religious teachings (Fix and Fix, 2002). Hence, the definition of faith-based organization which has been adopted in this study is a community service agency which explicitly identifies with a religious tradition or is auspiced by any religious organization or community. Programmes or services offered by a faith-based agency do not necessarily have any religious content.

This definition restricted the scope further to organizations which employ qualified social workers, but recognizes that this is a narrower definition than has sometimes been adopted by those writing about faith-based organizations (McGrew and Cnaan, 2006) who will refer to any kind of faith-related voluntary association, including churches, mosques, synagogues, and congregations, engaging in social welfare. Such a broad definition includes organizations where welfare provision is not among their key reasons for existence (Unruh and Sider, 2005).

Expressions of faith include the branding of an organization, organizational structure, how it understands its purpose, and the role of religion in service provision (Cnaan and Boddie, 2006; Unruh and Sider, 2005). Each of these expressions will now be considered in turn, along with the impact of changing circumstances upon the faith basis of welfare organizations.

\subsection{Branding}

The branding of an organization, including the name and signage, are often the first indications that it may have some faith basis but this is not necessarily an accurate predictor with some faith-based organizations intentionally choosing names which have no religious connotations (Ebaugh, et al., 2009). For example, in New York, a faith-based organization serving people with HIVIAIDS changed its name from Upper Room to Harlem United, downplaying its religious basis and seeking to emphasize the compassionate and non-judgemental nature of the services provided. On the other hand, having a name with religious connotations may be more a reflection of history than of contemporary circumstances. Although its name and symbol might suggest a religious organization, the Red Cross is typically now regarded to be an organization which had no religious origins but which is now ostensibly secular.

An analysis of the names of the approximately 50 publicly listed member organizations of Catholic Social Services reveals considerable diversity in naming. Member organizations had names which could be categorized as follows:-

1. Explicitly Catholic (e.g. CatholicCare)

2. Obviously Catholic to anyone who knows some basics about Catholic culture (e.g. Corpus Christi Community)

3. Obviously Catholic to those with some advanced knowledge about Catholicism (e.g. MacKillop Family Services)

4. $\quad$ Of some religion persuasion (e.g. Bethlehem Community Inc.)

$5 . \quad$ Of no obvious religious persuasion (e.g. Keysborough Learning Centre)

The importance of the names was discussed by a number of the Australian research participants, particularly in respect of many of the welfare agencies associated with Roman Catholic dioceses across the country changing their name from 'CentaCare' to the more ostensibly religious 'CatholicCare' which was commented on by social workers working for other organizations. One explanation given to me was that this name change was premised on a belief that this would endear the agencies more to the Catholic community by being more upfront as to this being a religion response to the welfare needs in the community. Observations from Australian social workers in Catholic welfare organizations included the comment:

"In our diocese, they think people don't see CentaCare as Catholic, you know, as a response from the religion to welfare. So they think the name, if you call it CatholicCare, people when they see CatholicCare in the paper will think here is the church doing something good." 
However, concerns were also raised that this might alienate potential service users and it was observed that such changes may be more about serving the needs of the religious faithful than in affecting how services are provided.

A further complication with naming is that some external programme funding requires host organizations to promote the name of the programme rather than of the auspicing organization. This may include using programme rather than agency letterhead, such that service users may be quite unaware that the services they are receiving are actually being provided by a faith-based organization.

Acknowledging that the distinction between religious and cultural symbols can be blurred (Netting , 2004), visual branding may nevertheless is used to promote messages as to the extent to which an organization is faith-based (Ebaugh et al., 2003). In an organization where some research participants actually questioned whether or not it was really 'faith based', it was noted that the symbol of the cross on the logo had become much less noticeable on a recent revision. This does not necessarily reflect any lessening of religious faith in the organization's underpinnings or values but may represent a conscious decision that their faith is best expressed in how they treat service users rather than in the use of symbols or signage (Tangenberg, 2005).

How organizations brand themselves is not only important in respect of communications with service users, but also to other stakeholders including donors. In an analysis of religious welfare in Lebanon, it was observed that whereas some organizations appealed to donors on the basis of being a 'civilizing force', others marketed donations as being a form of religious 'worship' (Jawad, 2009). However, despite what may seem apparent branding as being faith based, organizations may not be recognized as such in the wider community. For example in the UK, the Charity Commission for England and Wales does not necessarily classify welfare organizations as having a faith basis even though this might be implicit in their name, such as Jewish Care. Only organizations which explicitly state their objectives as religious rather than welfare provision are readily identifiable as having a faith basis (Charities Aid Foundation, 2013).

\subsection{Organizational Structure}

Whether or not indicated in their name, faith-based organizations typically have some degree of affiliation with a religious constituency, and it is this religious affiliation that differentiates them from their secular counterparts (Ferris, 2005). This may include welfare services auspiced by local groups or congregations, those at the district or diocesan level, and independent welfare organizations that are affiliated with one or more faith communities (Sinha, 2013). Furthermore there are organizations with a faith basis which may operate independently of institutional religion and have only informal connections with religious hierarchies (Deines, 2008), although they may have had such relationship previously.

Both national and religious characteristics may influence the organization of faith-based welfare services. Over the past decade and a half, much of the literature which has emerged concerning faith-based welfare provision and which has originated from the US has focused on initiatives provided by local faith congregations (Boddie and Cnaan, 2006), particularly from those associated with Protestants forms of Christianity (Unruh and Sider, 2005). However, some religions such as Islam and Catholicism have more of a propensity to develop centralized services which may be organized on a national or regional basis (Sinha, 2013). Such services are about a need for taking communal responsibility for members of society experiencing disadvantage rather than an explicit faith-based identity. Hence, within a nation such as the US, it has been proposed that models for analysing Protestant faith-based initiatives may have limited utility in other settings (Smith and Sosin, 2001).

In contrast to the US, Australian faith based welfare organizations are often associated with religious which have strong national or international structures, resulting in welfare agencies often being organized at regional level (Karim, 2005). Particularly since the mid-1990s, the welfare agencies of the major Christian communities in Australia have formed alliances with similar agencies from either the same or from other regions. This has led to the establishment of some large organizations under a single management structures, agencies such as CatholicCare, Anglicare, and UnitingCare. The trend of federating welfare organizations associated with a particular religion under a single umbrella is not confined to Australia but has also occurred in the other countries worldwide (Vanderwoerd, 2004). 
A key aspect of organizational structures concerns decision-making process within organizations. It may be important that the leadership is both skilled in managing a welfare agency and that there are processes reflecting the religious belief of the religious auspice (Schneider, 1999). Whereas in some faith based welfare organizations the major decisions are made by management groups controlled by the religious auspice. In others, the auspicing group may be entitled to nominate some but not all members of a board of management. Furthermore, there may be rules as to how many board members are required to be co-religionists (Sinha, 2013).

A mix of motivations for appointment to a board management of a faith based organization can lead to a decision-making which is based on maintaining ethics or values rather than purely rational grounds (Torry, 2005). Hence, Clarke and Jennings (2008) have proposed that the term 'faith-based organizations' refer to any organization that derives inspiration and guidance for its activities from the teachings and principles of the faith. But just because people claim to believe in God or some other deity does not necessarily result in a consensus as to what this means, and the implications for service provision (Dezerotes, 2009)

While some may argue that this is no more than wishful thinking, it has been declared that faith based organizations have a set of characteristics that distinguish them from their secular counterparts. The language of faith, the religious idiom, frequently better reflects the cultural norms in which the poor and marginalized operate (Clarke and Jennings, 2008, p. 15).

Alternatively, faith based organizations may reflect the cultural norms of the groups which established them. For example, in Indonesia five types of religious welfare organizations have been identified; organizations established and managed by religious orders, charitable organizations set by elite families associated with a religious tradition, religious organizations associated with popular political movements, international humanitarian relief organizations, and religious organizations closely associated with the state. Not only are these organizations distinguishable in terms of organizational structure, but also in terms of their aims or mission (Jawad, 2009).

\subsection{Purpose}

Although faith based organizations are those that derive their identity and purpose from a particular or spiritual tradition (Palmer, 2011), organizations which emerge from the same religious tradition may develop divergent understandings as to what their purpose should be (Cameron, 2004). For example, Islamic social teachings has been regarded as 'the most systematic and thorough attempt by a religious faith to articulate its position on social policy', and frequently informs understandings of social responsibility and welfare provision but can lead to radically different outcomes depending on how it is interpreted. However, although both justices for the individual and in society are recognized, interpretations of Islamic social teaching often give preference to one or other of these emphases (Ramadan, 2010).

Some religious organizations have understood their purpose in the wider world to consist of providing services to disadvantaged members of the community with little or no expectations of altering the religious beliefs and practices of those to whom the services are provided (Davies-Kielda, 2007). To guard against accusations of proselytizing, some faith based organizations make it known to staff that they may face being dismissed from their position if they seek to convert service users (Conradson, 2011), while in others staff are encouraged to change the topic when service users raise issues of a religious or spiritual nature (Pipes and Ebaugh, 2002). Elsewhere however, the hope of religious conversion underpins service provision by some religious organizations. This can range from low-key invitations about which the recipient is made aware that their decision to participate or not in religious activities will have no impact on receipt of welfare services. Through to coercive or manipulative attempts involving inducements for those who choose to become involved in a religion, including providing services only to individuals who have participated in religious activities such as prayers or worship conducted by the organization (Belcher and DeForge, 2007).

Hence, Gilligan (2010) has identified two contrasting approaches to faith based social work which he has labelled 'liberal or open' and 'fundamentalist or exclusive'. In the former approach, religious belief are recognized as an underlying motivation to service provision and the religious underpinnings of a programme or agency may in fact emerge in the public sphere as a commitment to care rather than use explicitly religious language, whereas the latter is premised on the belief that religious salvation is the ultimate imperative. 
This question is whether faith based welfare organizations are called to be the 'mouthpiece of God' or 'the quiet voice of God'. In other words, are they called to preach or to be a presence through service provision? This is far from a new question, and in her analysis of welfare services in Malaysia, Gill (2012) has reported that a far more influential factor in the structuring of faith based welfare services was the distinction between 'kaum muda' and 'kaum tua' understandings of the Muslim duty and service. Confident in their own forgiveness, 'kaum tua' became involved in charity as a way of bringing people to God. Consequently, they measured their success in terms of conversions gained rather than poverty relieved. Their good works served as a demonstration of individual conversion, fulfilling their duty as Muslims to show love for others. Because they understood poverty to be a result of sinfulness, 'kaum tua' offered forgiveness rather than condemnation, and preferred to see the institutions they established as 'homes' rather than asylums of reformatories. However, their compassion was tempered by a sense of moral superiority which justified their interference in the lives of those who came to them for help. 'Kaum muda' on the other hand, value the poor because their suffering was seen as bringing them closer to God. Charity was not about moral superiority, but about bearing witness and adhering to the values of the Quran, seeing the mercy of God rather than the sinners in the individual who came to them for help. In their approaches, they looked for outward conformity rather than individual conversion, believing that ritual and practice would bring the poor to salvation.

Payne (2005) paints a similar story in Britain in the $19^{\text {th }}$ century where the evangelicals most likely to regard themselves as successful if they achieved conversion. Such tensions were also being played out in the US where some early leaders in the Charity Organizations Societies warned volunteers that the aim of 'friendly visiting' was not spiritual conversion but rather to provide charity to the most needy and vulnerable members of the community (Scales and Kelly, 2011).

Clarke's (2008) writing on the role of faith based organizations in development studies has proposed that rather than a dichotomy between implicit and explicit expressions of religion, a continuum is required. In particular, he notes four main ways in which faith manifests itself in the work of faith based organizations; passive, active, persuasive, and exclusive.

Passive means the teachings of the faith are subsidiary to broader humanitarian principles as a motivation for action and in mobilizing staff and supporters and play a secondary role to humanitarian considerations in identifying, helping, or working with beneficiaries and partners.

Active way means faith provides an important an explicit motivation for action and in mobilizing staff and supporters. It plays a direct role in identifying, helping or working with beneficiaries and partners, although there is no overt discrimination against non-believers and the organization supports multi-faith cooperation.

Persuasive way is when faith provides an important an explicit motivation for action and in mobilizing staff and supporters. It plays a significant role in identifying, helping or working with beneficiaries and partners and provides the dominant basis for engagement. It aims to bring new converts to the faith and to advance the interests of the faith at the expense of others.

Exclusive way means faith provides the principal or overriding motivation for action and in mobilizing staff and supporters. It provides the principal or sole consideration in identifying beneficiaries. Social and political engagement is rooted in the faith and is often militant or violent, and directed against one or more rival faiths (Clarke, 2008, p.32-33).

Clarke notes that it is the first and second categories of faith-based organisations that are most likely to attract support, including financial donations, in the wider community. Furthermore, such organisations may truly believe that addressing humanitarian concerns is more urgent than addressing religious practice. For example, Islamic Relief acknowledged that the facilities for community prayer available in a refugee camp were inappropriate but considered its priorities to be concerned around ensuring basic living standards in terms of food, shelter, water, and sanitation (Shamsuddin, 2012). Nevertheless, potentially all four of Clarke's organizational categories allow for faith-based organisations to prophetic and to care for the vulnerable. Moreover, although explicitly religious outcomes are only mentioned in the latter two of Clarke's categories, to some extent these may also underpin the expectations of stakeholders in the first two categories.

While conversion is often considered in respect of non-members becoming active in, and taking on the values of a new religion, an expectation of conversion may also be placed upon members whose beliefs or actions are considered to be in opposition to religious teachings. For example, Islamic charities in Somalia often seek to create good Muslims who will purify their practice rather than win new converts to Islam (Kroessin and Mohamed, 2008, p. 207). An example of this may also be found in Malaysia where the message of an education campaign aimed at Muslim men was that 'Violence against women is illegal and betrays the example set by our Prophet' (Ahmad, 2012). 
Whether faith-based organisations view their purpose as predominantly serving co-religionists or outsiders is also critical, given that services provided by religious agencies to members of their own religion may vary considerably from services aimed at the wider community (Thyer, 2006; Baker, 2012). For instance, faith-based welfare organisations particularly those associated with immigrant groups, will often provide services only to their own community members (Clarke, 2008), and in turn, may be preferred by members of their communities for their ability to provide culturally and linguistically sensitive services. Furthermore, organisations associated with minority religions are often concerned to pass their faith on to their youth which is not only an investment by religious organisations in the long term future of their communities but also because this contributes to civil society more generally by being a moderating influence against extremism (Green, 2010).

Seeking to understand the purpose of a faith-based organisation requires going beyond focusing on the attributes of the organisation and taking account of expected service user characteristics particularly in respect of their religious beliefs or affiliations. Whether recipients of welfare services are viewed primarily as service users or as potential converts will affect both how services are provided and the service user experience.

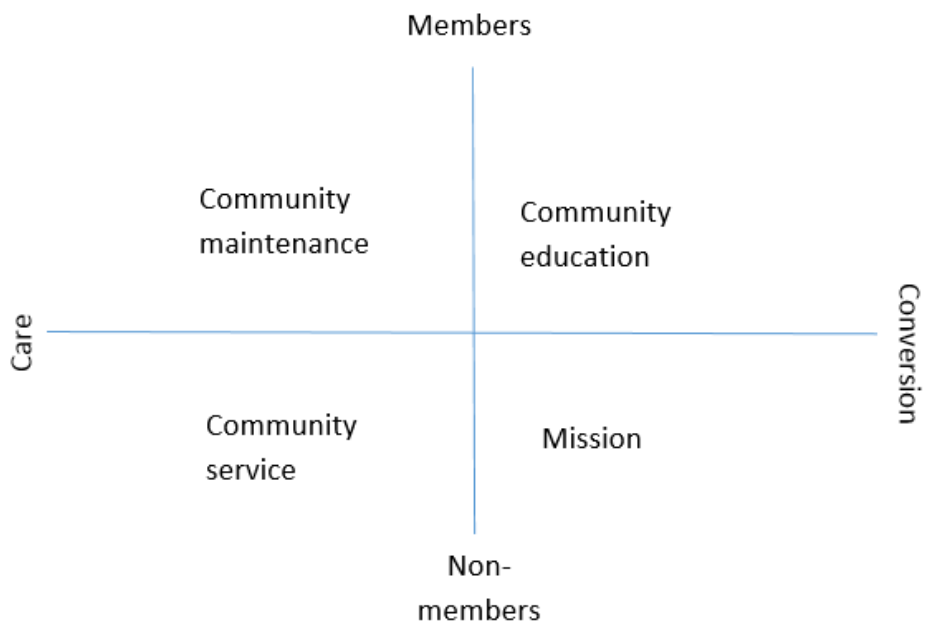

Figure 1: Service orientation of faith based organisations as determined by target group (members versus non-members) and service aim (care versus conversion)

The above figure is designed to understand the service orientation of faith based organisations as determined by target group and service aim. It consists of two intersecting axis. The first axis relates to the target group and whether it is exclusively or primarily aimed at members or non-members of a religious community. This crosses another axis in which the emphasis of service provision varies, ranging from being primarily concerned with care to a strong emphasis on conversion.

The emphasis of organisations which primarily provide care services for members of a faith community may be typified as 'community maintenance'. An example of this would be the welfare programmes of the Church of Sweden. With the majority of Swedes identifying as members of the church, the welfare work of the church is primarily to its own members. But given that religion is widely regarded to be a private matter in Swedish society, services provided by the church place their emphasis on care rather than on religious conversion. Similarly many Jewish welfare organisations tend to provide services largely to their own members, and actively seeking converts is not a feature of Judaism(Crisp, 2013; Beckman, 2006).

In contrast to the Church of Sweden, services provided by welfare organisations associated with the Catholic Church in Australia which are often aimed at the wider community tend to be characterized by an ethic of 'community service' (Crisp, 
2013). As might be expected in settings which are staffed by welfare professionals, religious conversion is not considered a primary aim of welfare provision in programmes characterized by community service (Smith and Sosin, 2001).

Services aimed at community members which place an emphasis on religious conversion will have a 'community education' focus. An example of this is the domestic violence prevention programme mentioned previously which appeals to the religious beliefs of Islamic men.

The fourth quadrant which comprises organisations and programmes aimed at non-members with a strong religious focus may be typified as 'mission'. Staff are typically required to be of the faith and programmes have a strong religious content. Many faith-based welfare programmes offered in many South East Asian countries such as Indonesia and the Philippine which include religious content may be characterized in this quadrant (Tirrito and Cascio, 2003).

Any typology of faith-based welfare services will have its limitations not at least of which includes considerable variation in praxis within and between religious traditions (Dinham, 2009). It is recognized that the predominant emphasis of organisations is not necessarily fixed within a particular quadrant and may vary both across time and between different programmes conducted by an agency (Unruh and Sider, 2005). Furthermore, while recognizing that real organisations and programmes rarely fit perfectly into ideal types, this framework demonstrates the diversity of faith-based welfare organisations, although it is recognized that the predominant quadrants may vary in different religious and national contexts. Furthermore, although it has sometimes been proposed that the opposite of a programme or agency which is highly explicit in its religious identity is one with a secular orientation, the framework recognizes that such distinctions have been questioned.

A further aspect of purpose relates to the financial aims of faith-based organisations. While faith-based organisations to be non-profit voluntary organisations (Hiemstra, 2002), they may need to generate some income to supplement state funding and donations. In some organisations this may lead to ensuring that the costs of providing the service are paid for by service users (Valins, 2011). However rather than requiring fees to be paid by the users of all services, the aims of some programmes may include generation of a profit which may be used to subsidise other services provided by the organisation (Torry, 2005).

\subsection{Service Provision}

Often closely related to how an organisations views its purpose is the nature of service provision. Faith-based organisations range in scope from those offering a single service to large multi-programme and multi-agencies which provide services to a wide range of needs within communities on a local, regional, national, or international basis (Rogers, 2005; Berger, 2003). However, due to the differing needs, resources, and priorities in different communities, effective faith-based organisations need to find ways of working which are appropriate in and for the communities where they work. In addition to being providers of welfare services, faith-based organisations may also be involved in public debates about the nature of service delivery (Angell, 2010).

It is important to distinguish 'faith-placed' services which use the resources of a religious group, but that are otherwise quite separate from 'faith-based' services which are provided by a religious organisation either for its members or the wider community (Fagan, 2010). In delineating the place of professional social work from the broader activities of religious groups or organisations, Torry's (2005) definition of faith-based organisations is those 'organisations firmly related to a religious tradition but which do not have a religious activity as their primary aim'. He argues that 'such organisations occupy a place between religious organisations and secular organisations, and deserve a treatment of their own'. This is in contrast with the more common binary view of organisations as either religious or secular (Linden, 2008), although it is noted that in some countries such as Greece (Fouka,2012) and Italy (Backstrom, 2011), even the distinction between religious and secular is less than clear.

For Torry (2005), the difference between religious and faith-based organisations is not whether they are run by clergy or laity but rather the activities they undertake. Hence, as long as there is some religious connection or underpinning, the work cannot truly be called secular. Similarly Belcher and DeForge $(2007)$ have classified organisations on the basis of activities and in their writing about social work in faith-based organisations, deliberately excluded services which sought to proselytise service users. Although no such exclusion was made in this current volume, the focus on faith-based organisations which 
employ professional social workers resulted in the majority of social workers interviewed working in organisations that would be categorised by Torry as faith-based rather than religious and reflects that it is more common for social workers to be employed in community agencies than in local parishes where the primary aims are religious (Ebear, 2008).

For Unruh and Sider (2005), the critical question seems to be not whether the organisations is faith-based but whether or not the programmes it delivers are. They note that the programmes run by a single organisation can range from those with a very explicit faith element in the programme, requiring staff to have a strong faith commitment consistent with the programme's content, and no religious requirements on the staff employed to run such programmes, with a range of types in between these ends of a continuum. As they consider a wide range of factors including mission statement, founding, religious affiliation, organisational decision-making, sources of funding, in addition to religious content in programmes and staffing, Unruh and Sider demonstrate why there is such a broad range of organisations which come under the umbrella of being faith-based. However, an important critique of their work is that Unruh and Sider have created a typology of faithbased organisations which best fits with direct practice and does not readily apply to other aspects of social work such as advocacy and policy development (Netting, 2004).

\subsection{Changing Circumstances}

Long term survival has required many faith-based organisations to change, innovate and merge with other similar organisations (Lake, 2013). In doing so, the nature of religious expression can change significantly. Small local initiatives have sometimes given impetus to the emergence of large welfare agencies, but while growth may result in faith-based organisations becoming economically more viable, it can also bring challenges for faith-based organisations in maintaining their faith identity (Ferguson, 2004). Similarly, as the needs of the target population change, faith-based organisations may need to redefine their purpose. In particular, it has been recognised that as the needs of ethnic communities change, ethnic religious organisations providing welfare to their members sometimes find themselves with the potential capacity to provide services to members outside their communities (Boddie, 2011).

Changes sometimes result in organisations becoming independent of their founders. While Netting (2004) proposed that if an organisation calls itself faith-based then it is the question which has been raised by Torry (2005) as to whether this can be so if the link with the founding vision or religious values is broken. This is particularly an issue concerning organisations which were originally established by religious groups and may have an ethos which reflects their religious origins but which are now community organisations with no formal link to religious groups (Middlemiss, 2006).

Faith-based organisations frequently claim themselves to be different from their secular counterparts whether this be in respect of what or how services are provided (Davies-Kielda, 2007). Yet, despite such perceptions, there is no single definition as to what a faith-based organisation is and against which claims of distinctiveness may be judged. Furthermore, Ebaugh et al. (2006) have previously concluded that there are multiple dimensions to religiosity among faith-based organisations and that scoring high on one of these dimensions is not a predictor of scoring highly on another. In particular, organisations which have a strong faith identity in terms of name or organisational structure often provide seemingly secular services where there is no explicit religious content (Vanderwoerd, 2004). Thus, although this review has not been able to conclusively resolve the question of what is a faith-based organisation, it does explain why seemingly very different organisations, in respect of their branding, organisational structure, purpose and service provision, can claim to be faithbased. Perhaps it is not how organisations perceive themselves but how they are perceived by others that is the critical question as Rogers et al. (2005) mentioned:

"What makes an organization faith-based? It is not in these external variables of name or location or organisational type, then perhaps it is in the meaning given to the context by others"

\section{Understanding FBOs in their relation to NGOs}

While religious groups are generally primarily concerned with the spiritual well-being of their members, many have also long been interested in addressing the physical well-being of their communities as well. Indeed, for many this has often 
been a core aspect of their existence (Hovland, 2008). This concern with physical well-being is often experienced and delivered through faith-based organizations (FBOs) affiliated with religious communities (Clarke, 2008; Clarke and Jennings, 2008; Clarke et al., 2011). Clarke (2006) suggests these agencies can, in fact, be considered forerunners to modern NGOs as they have been providing support for the poor for a very long time.

Yet, for decades FBOs were ignored in mainstream discussions of community development (Willis, 2013). However, FBOs have begun to initiate contact with aid donors in recent years to seek increased involvement (and funding) in community development interventions (Marshall and Van Saanen, 2007). Therefore, the exclusion of FBOs from community development work is now diminishing.

There are seven broad categories in the literature, ranging from FBOs being considered in all substantive matters as being the same as NGOs to being considered entirely incomparable - with a range of relationships in between (Clarke, 2015). In light of this review a final typology will be proposed which suggests that understanding FBOs is perhaps best done by considering the range of its constitutive identities, including that of NGOs.

The first manner in which FBOs are often compared to NGOs in the FBO literature are as organizations that sit within the intersection of NGOs and religious organizations (refer Figure 1) - that is, these FBOs can be classified as both, NGOs because of the work in which they are engaged, and as religious organizations due to their faith-based identity. The consequence of this dual identity is that these organizations are quite distinct from both, solely secular development focussed NGOs and solely non-development sectarian organizations (Haynes, 2009; Nishimuko, 2008). In this sense, FBOs have two identities (Lloyd, 2007; James, 2009). As Flannigan identifies, this dual citizenship or intersection approach can be found in FBOs of all faiths, including not just Christian, but also Buddhist, Hindu, Jewish and Muslim organizations (Jaffrelot, 2008; Lunn, 2009). This typology recognizes that while NGOs and religious organizations are distinct, that a number of organizations (FBOs in this instance) do straddle both worlds. The point of distinction between FBOs and NGOs in this typology is the religious basis that gives rise to the FBOs development motivation. This typology though, does not clarify whether there are clear distinctive approaches to development programme implementation within communities.

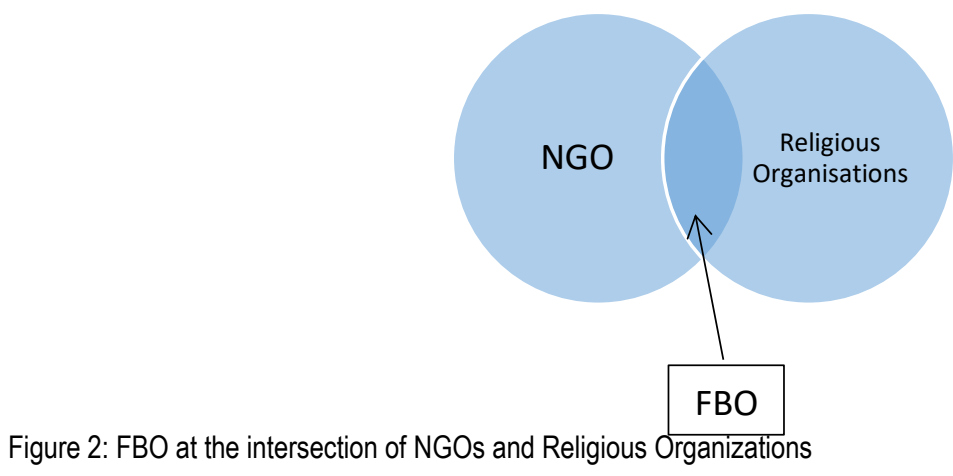

The second manner in which they are sometimes conceived is completely distinct and separate from NGOs. While they may undertake similar activities and share much of the same 'DNA', it is precisely their religiosity that makes them incomparable to NGOs. This religious motivation that underscores their existence is sufficiently differentiated from NGOs to render them completely distinct entities (James, 2009). In this sense, the work that FBOs undertake is substantially different from NGOs as it is informed by religious principles and teachings that if not incompatible with the underpinnings of development activities undertaken by secular NGOs are at least sufficiently differentiated to result in a distinct development approach. This alternative approach is largely based on alternative development values (Olson, 2008). Clarke (2006) puts forward three types of FBOs that fall into this distinct from category. The first are apex bodies or faith-based representative organizations. The second are FBOs that focus on socio-religious goals and the final type of FBO that is distinct to NGOs, are those that engage in illegal and sometimes violent activities. 


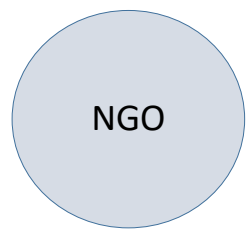

Figure 3: FBO as completely separated from NGOs

The third manner in which FBOs are sometimes conceived sits in binary opposition to this previous approach. The value of this typology is that it does away with looking for differences and focuses on the similarities and primarily the purpose of the FBO which is, to respond to the humanitarian imperative (Berger, 2003). Therefore, in this sense they are effectively the same as NGOs and can quite rightly be described as NGOs themselves - in more plain language, they are interchangeable (Marshall, 2005). However, the failure of this typology is that it does not give weight to the motivation of FBOs doing this development work. It does not show the differences in value sets, motivations, linkages to communities and broader networks that FBOs have in contrast with secular NGOs. This difference in values, while perhaps not obvious in programme implementation, can be an important point of distinction between NGOs and FBOs.

Figure 4: FBO and NGO as interchangeable

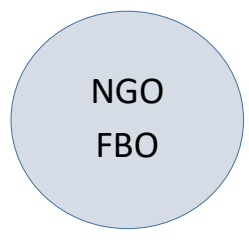

A fourth understanding of the difference between NGOs and FBOs is to consider FBOs a subset of NGOs in the sense that the term NGO is quite broad and includes an array of organizations that are non-governmental and that FBOs are one such grouping of organizations (Audet et al., 2013; Thomas, 2004). As the NGO sector therefore, is more heterogeneous than homogenous, a binary distinction based on faith motivation is somewhat artificial and does not capture the complex nature of civil society with competing priorities, networks, aspirations and agendas. The advantage of this typology highlights the similarities in structures, functions, etc. as well as the fact that many in both secular and religious NGOs have a faith motivation for what they do (Leurs, 2012). However, the model does fall short in not embodying the differing relationships FBOs have with donor and recipient communities, compared to secular NGOs (McDui-ra and Rees, 2010).

Figure 5: FBO is subset of NGO

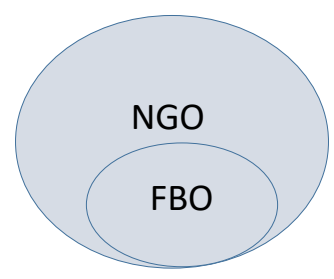

This is slightly different to the fifth manner in which to understand FBOs and they are sometimes described as FBOs coexisting with NGOs. In this way of understanding, FBOs are given equal weightage as NGOs as key stakeholders within civil society each playing important but distinct roles in holding the state and market to account. However, FBOs are also seen to play a role outside their own faith boundaries (Lunn, 2009). Moreover, FBOs play a very significant role in the 
provision of social services, often on behalf of governments unable to establish the trust and relations required to engage in difficult communities (Clarke et al., 2011; Nishimuko, 2008).

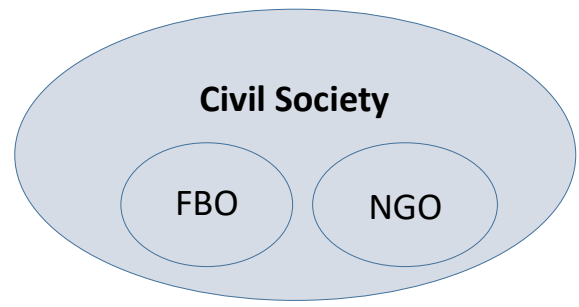

Figure 6: FBO coexisting with NGO

A sixth manner in which FBOs might be understood is an atomistic group of many

individual and distinct organizations that have many differences but a common faith-based

premise. This approach accounts for the marked differences between FBOs that are small micro agencies located at a congregational level as well as international aid agencies operating transnational partnerships (Boehle, 2010; James, 2009; Bradley, 2009). Another interesting aspect captured within this typology is the nature of culture and religious interpretation that affects how FBOs operate within the development sector (Saddiq, 2009). Thus, even within FBOs sharing the same faith, there can be wide distinctions in how each FBO can operationalize this faith.

Figure 7: Atomistic view of FBO

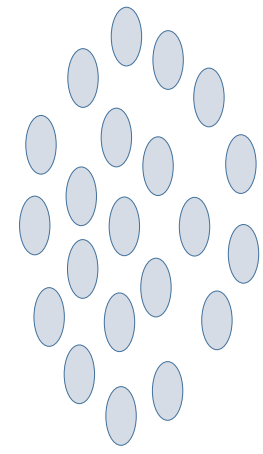

The seventh model which may integrate all the others and better reflect the distinctiveness of FBOs might be understood as having in relation to NGOs. FBOs are constitutive of a number of bodies that are involved in development activities. FBOs can claim heritage and relationship to NGOs, religious organizations, civil society organizations and communities. In this sense they are somewhat creatures with a 'Frankenstein' nature - distinctive and existing in their own right, but drawing on aspects and parts of other stakeholders. In this sense, FBOs are distinct from NGOs, but containing elements of NGOs within them (Lunn, 2009). By drawing on a range of heritages and holding membership within different areas of society, FBOs are a unique amalgam working within the development sector to improve the lives of the poor with this approach.

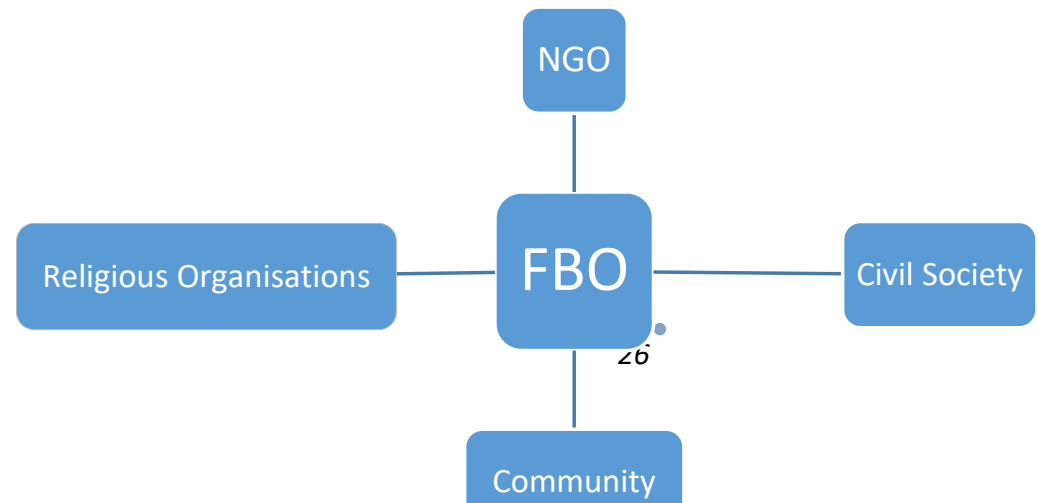


Figure 8: Constitutive view of FBO

\section{References}

[1] Audet, F., Paquette, F. and Bergeron, S. (2013), Religious Non-Governmental Organisations and Canadian International Aid,

[2] Berger, J. (2003), Religious Non-Governmental Organizations: An Exploratory Analysis,

[3] Boehle, J. (2010), Religious NGOs at the UN and the Millennium Development Goals: An Introduction,

[4] Bradley, T. (2009), A Call for Clarification and Critical Analysis of the Work of Faith-Based Development Organizations (FBDO),

[5] Clarke, G. (2006), Faith Matters: Faith-Based Organisations, Civil Society and International Development. London: Routledge.

[6] - (2008), Faith-Based Organisations and International Development: An Overview, New York: Palgrave Macmillan.

[7] Clarke, G. and Jennings, M. (2008), Development, Civil Society and Faith-based Organisations: Bridging the Sacred and the Secular. New York: Palgrave Macmillan.

[8] Clarke, M., Charnley, S. and Lumbers, J. (2011), Development in Practice, Buckingham: Open University Press.

[9] Davies, Thomas (2014). NGOs: A New History of Transnational Civil Society. New York: Oxford University Press.

[10] Haynes, J. (2009), Conflict, Conflict Resolution and Peace Building: The Role of Religion in Mozambique, Nigeria and Cambodia. New York: Crown Publisher.

[11] Hovland, I. (2008), Who's afraid of religion? Tensions between mission and development in the Norwegian Mission Society, in Clarke, G. and Jennings, M. (ed.), Development, C Civil Society and Faith-based Organisations: Bridging the Sacred and the Secular, New York: Palgrave Macmillan.

[12] Jaffrelot, C. (2008), Hindu Nationalism and the Social Welfare Strategy. New York: Palgrave Macmillan.

[13] James, R. (2009), What is Distinctive About FBOs? How European FBOs Define and Operationalise Their Faith,

[14] Leurs, R. (2012), Are Faith-Based Organisations Distinctive? Comparing Religious and Secular NGOs in Nigeria,

[15] Lloyd, R. (2007), Foreign Fields: International Aid and Faith-Based Organizations, 
[16] Lunn, J. (2009), The Role of Religion, Spirituality and Faith in Development: A Critical Theory Approach,

[17] Marshall, K. (2005), Africa: How And Why Is Faith Important And Relevant For Development? Berkley: Centre for Religion, Peace and World Affairs.

[18] Marshall, K. and Saanen, M.V. (2007), Development and Faith: Where Mind, Heart and Soul Work Together, Cambridge: Polity Press.

[19] Matarrita-Cascante, D. (2010). Beyond growth: Reaching tourism-led development. Annals of Tourism Research, 37(4).

[20] Matarrita-Cascante, D., Brennan, M.A., \& Luloff, A.E. (2010). Community agency and sustainable tourism development: The case of La Fortuna, Costa Rica. Journal of Sustainable Tourism, 18(6).

[21] Matarrita-Cascante, D., Stedman, R., \& Luloff, A.E. (2010). Permanent and seasonal residents community attachment in natural amenity-rich areas: Exploring the contribution of community and landscapebased factors. Environment and Behavior, 42(2).

[22] Mcduie-Ra, D. and Rees, J.A. (2010), Religious Actors, Civil Society and the Development Agenda: The Dynamics of Inclusion and Exclusion,

[23] Nishimuko, M. (2008), The Role of Faith-Based Organizations in Building Democratic Process: Achieving Universal Primary Education,

[24] Olson, E. (2008), Common Belief, Contested Meanings: Development and Faith-Based Organisational Culture,

[25] Saddiq, N. (2009), Capacity Building and Islamic FBOs: Insights from Malawi,

[26] Taylor, G.S. (2007). What is community development? Brazos: Agricultural Communications, The Texas A\&M University System.

[27] Theodori, G. (2000). Level of analysis and conceptual clarification in community attachment and satisfaction research: Connections to community development. Community Development, Journal of the Community Development Society, 31(1), 35-58.

[28] Theodori, G. (2001). Examining the effects of community satisfaction and attachment on individual well-being. Rural Sociology, 66(4), 618-628.

[29] Theodori, G. (2007). Preparing for the future: A guide to community-based planning. Starkville, MS: Southern Rural Development Center.

[30] Walzer, N. (2010). CDS at 40: The past leading to the future. Community Development, Journal of the Community Development Society, 41(4), 401-404.

[31] Wilkinson, K. (1991). The community in rural America. Middleton, WI: Social Ecology Press.

[32] Thomas, S. (2004), Faith and Foreign Aid: How the World Bank Got Religion and Why It Matters,

[33] Willis, O. (2013), Religion and International Development in the Canadian Academic Context, London: Macmillan. 